\title{
STATISTICAL ANALYSIS OF GPR AND SPT METHODS FOR SINKHOLE INVESTIGATION IN COVERED KARST TERRAIN, WEST-CENTRAL FLORIDA, USA
}

\author{
Henok Kiflu, Sarah Kruse \\ Dept. of Geology, University of South Florida, 4202 E. Fowler Ave., Tampa, Florida 33620 USA, \\ hgkiflu@mail.usf.edu,skruse@usf.edu \\ Michael Wightman \\ Geoview, Inc., 4610 Central Ave., St. Petersburg, Florida 33711 USA, mwightman@geoviewinc.com
}

\begin{abstract}
Sinkholes and sinkhole-related features in west-central Florida are commonly identified from surface penetration test (SPT) borings, which are located, in part, based on the results from ground penetrating radar (GPR) surveys. SPTs and GPR profiles yield complementary information-SPTs can indicate the presence of lowdensity soils or voids, while GPR profiles can resolve shallow stratigraphic indicators of subsidence. In GPR profiles collected at 103 residential sites in covered-karst terrain in west-central Florida, sinkhole-related anomalies were identified where GPR reflectors show downwarping, discontinuities, or sudden increases in amplitudes. We analyze the degree to which the shallow features imaged in GPR correlate spatially with the $\mathrm{N}$-values (blow counts) derived from SPTs at 103 residential sites. Results are used to examine (1) which SPT indicators show the strongest correlations with GPR anomalies, (2) the degree to which GPR surveys improve the placement of SPT borings, and (3) what these results indicate about the structure of sinkholes at these sites. We find a statistically significant correlation between GPR anomalies and low SPT N-values with a confidence level of $90 \%$. Logistic regression analysis shows that the strongest correlations are between GPR anomalies and SPT values measured in the depth range of 0-4.6 m. The probability of observing a GPR anomaly on a site will decrease by up to $84 \%$ as the minimum SPT value increases from 0 to 20 . Boreholes drilled on GPR anomalies are statistically significantly more likely to show zones of anomalously low SPT values than boreholes drilled off GPR anomalies. The odds ratio depends on how the threshold criteria for low $\mathrm{N}$-values are defined, with a maximum observed odds ratio of 2.89 . Several statistical results suggest that raveling zones that connect voids to the surface may be inclined, so that shallow GPR anomalies are laterally offset from deeper zones of low $\mathrm{N}$-values.
\end{abstract}

\section{Introduction}

Sinkholes are a common cause of damage to residential buildings and other infrastructure in the covered karst terrain of west-central Florida (e.g. Frank and Beck, 1991). Sinkhole activity can be manifested as recognizable topographic depressions that may evolve with time. However, identifying sinkhole potential in the absence of such surface subsidence features is a challenge.

Schmidt (2005) states that sinkhole investigations should be done in an integrated way that involves desk and site reconnaissance study, geophysical investigation, floor elevation mapping, geotechnical investigation and geological interpretation, laboratory analysis and structural analysis of the site. Standard penetration tests (SPTs) and cone penetration tests (CPTs) are the most common geotechnical field tests used in sinkhole investigation. SPTs are made by repeatedly vertically dropping a $63.5 \mathrm{~kg}$ hammer for $76.2 \mathrm{~cm}$ length until a total penetration of $45 \mathrm{~cm}$ is reached. The number of blows required to penetrate the last $30 \mathrm{~cm}$ is called the $\mathrm{N}$-value. The $\mathrm{N}$-value, or blow count, is related to the density of granular soils or stiffness of cohesive soils. Zones with low $\mathrm{N}$-values are expected in association with raveling into a sinkhole cavity or a dissolution cavity itself. However, Dobecki et al. (2006) have stated that blind drilling on sites would have low probability of intercepting a raveling zone and may instigate ground collapse incidents. Ground penetrating radar surveys are useful in identifying stratigraphic indicators of subsidence. These indicators include downwarping or, discontinuities in near-surface strata, or locally abrupt increases in GPR amplitudes. If borings were sited on GPR anomalies, the total number of borings could be minimized, decreasing total cost and minimizing unnecessary ground collapse incidents (Dobecki et al., 2006). 
Neither ground penetrating radar nor SPTs are in themselves definitive measures of the presence of an active sinkhole (e.g. Schmidt, 2005). This argument has also been made by others, including Zisman (2001), who developed a scoring method for characterizing sinkhole potential of a site using geological and geotechnical factors. Zisman (2001) developed his criteria based on experience gained in west-central Florida.

By analyzing relationships between GPR-determined "sinkhole" anomalies and SPT records, we can address questions about the strengths and limitations of each method for detecting sinkholes. We can also test hypotheses about sinkhole structure. For our study sites in west-central Florida we examine (1) which characteristics of SPTs show the strongest correlation with the presence of GPR anomalies, (2) the degree to which GPR surveys improve the placement of SPT borings over random siting, and (3) what we can infer about the structure of sinkholes at these sites. To do this, we analyze GPR and geotechnical data collected from 103 residential sites in west-central Florida for which sinkhole activity was suspected (Figure 1). Across these sites a total of 299 SPTs were run (Figure 1), or about 3 per site. We find that using GPR data does increase efficiency in finding low $\mathrm{N}$-value zones, and the effect is strongest for SPT values from shallow depths.

\section{Study area}

Most of the study area is characterized as lowland area, with Quaternary sediments overlying Tertiary carbonate rocks (Scott, 1988). Most of these sediments are unconsolidated sand, silty sand and sandy clay deposits that range in thickness from 0 to $>60$ meters (Figure 1). Other morphological features in the study area include plains, uplands, ridges and swamps. Carbonate rocks are exposed in places in west-central Florida (Florea, 2006) but not at any of the residential sites studied. At the study sites, the mean depth to groundwater was $2.6 \mathrm{~m}$, with a minimum depth of 0.46 meters.

\section{Field Methods}

Consistent methodology was used for ground penetrating radar surveys and geotechnical tests at the 103 residential sites shown in Figure 1. The GPR system works by emitting high frequency electromagnetic waves into the ground with a transmitting antenna and recording the reflected signals with a receiving antenna while both antennas are pulled across the ground. The

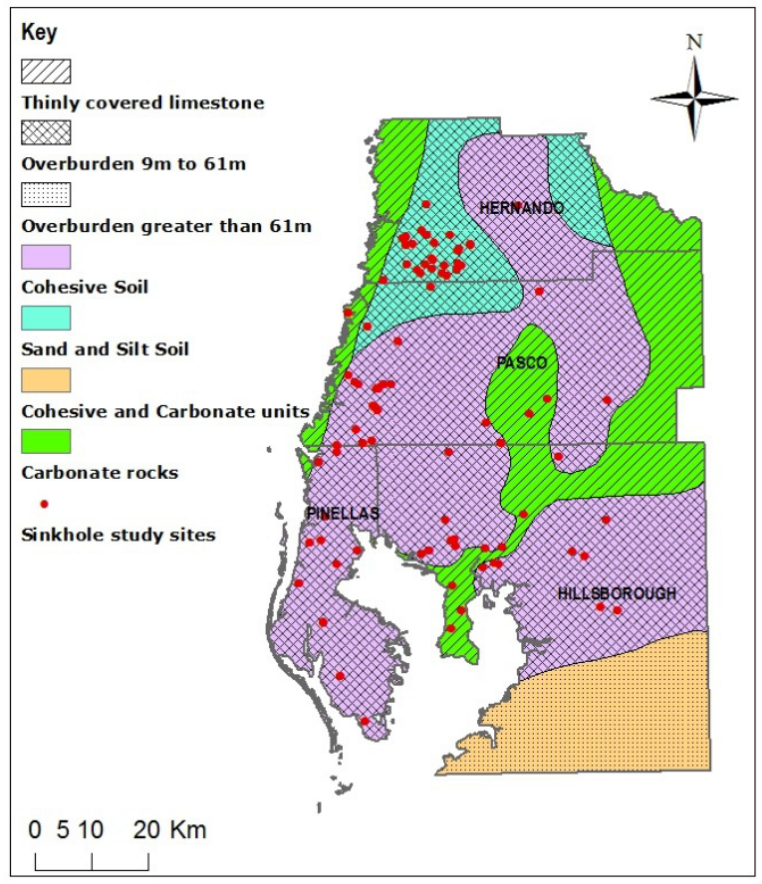

Figure 1. Study sites (red dots), soil type, and overburden thickness in west-central Florida. Capitalized labels show counties. GPR surveys and SPT borings were conducted at each study site. Soil types and overburden thickness from Sinclair et al. (1985). County boundaries from FDEP (2013). GPR profiles were collected by GeoView, Inc and SPT borings by Ground Down Engineering, Inc.

amplitude of the reflected signals is related to contrast in dielectric permittivity of subsurface materials. In this study, a Mala GPR system was used to collect ground penetrating radar (GPR) profiles, generally using a $3 \mathrm{~m}$ grid spacing. The data were collected using $250 \mathrm{MHz}$ and $500 \mathrm{MHz}$ antennas for internal and external parts of residential sites respectively. The depth of penetration for GPR surveys is usually less than $12.2 \mathrm{~m}$. The bedrock depth for the study area ranges from 0 to $31.5 \mathrm{~m}$ with a mean depth of $13.1 \mathrm{~m}$. Hence, GPR surveys rarely if ever image subsurface cavities. This is related to the penetration limitation and to the fact that the underlying cavity may not be directly below the site or survey lines. However, sites affected by sinkholes may have raveling activity at depth which may result in downward migration of granular sediments from the shallow soil layers. This movement can make near surface granular soils less dense and result in downward deformation of cohesive layers. These processes result in recognizable features in the radar images, if they are within the range of penetration of the GPR signal. These associated 
features, recognized as locally downwarping layers, lateral discontinuities, and abrupt increases in amplitude, were subjectively identified from the GPR images. Areas encompassing anomalous sections of GPR transections were then delineated.

GPR surveys were followed by geotechnical field investigations, including drilling, soil sampling, laboratory analysis and insitu field tests. A minimum of three boreholes were drilled in $95 \%$ of the sites. Borehole sites were chosen to include both areas within and outside of GPR anomalies. The average depth of boreholes was $17.4 \mathrm{~m}$. Standard penetration tests (SPT) were conducted in all boreholes. SPTs were usually started at $1.8 \mathrm{~m}$ depth and continued downward at $1.5 \mathrm{~m}$ intervals below a depth of $3 \mathrm{~m}$.

A number of methods exist to characterize the strength of soil based on SPT values (e.g. Carter et al., 1989). Following Meyerhof (1956) and Peck et al. (1974), granular soils are considered loose if they have an $\mathrm{N}$-value less than 10 and are considered dense if they have $\mathrm{N}$-value above 30 .

\section{Statistical Analyses: Results and Discussion}

Because both SPT results and GPR anomalies are indirect and imperfect indicators of sinkhole processes, we can use neither as a direct proxy for the presence of a sinkhole. Thus it is valid to examine SPT data as a predictor of GPR anomalies, or vice-versa. Here we do both, but we use different statistical methods because we are addressing different questions with each analysis.

The SPT data contain a range of values ( $\mathrm{N}$-values) that vary as a function of depth at each boring location, at intervals of $\sim 1.5$ meters. In contrast the GPR data are categorical data, either "yes" an anomaly is defined at the given location, or "no", no anomaly is observed at that point. SPT data from 0-12.2 meters depth are analyzed, so as many as $9 \mathrm{~N}$-values are considered per SPT site. These measurements typically span transitions between surficial sands to silty sands. At some sites clays are encountered. To examine at least indirectly the role of the stratigraphy in the SPT readings, the SPT records are divided into three depth zones, as shown in Figure 2. For the analysis below, data were treated with ArcGIS 10.1, AutoCAD 2010, and SAS 9.2 software, and using codes written in Perl and Matlab R2010a.

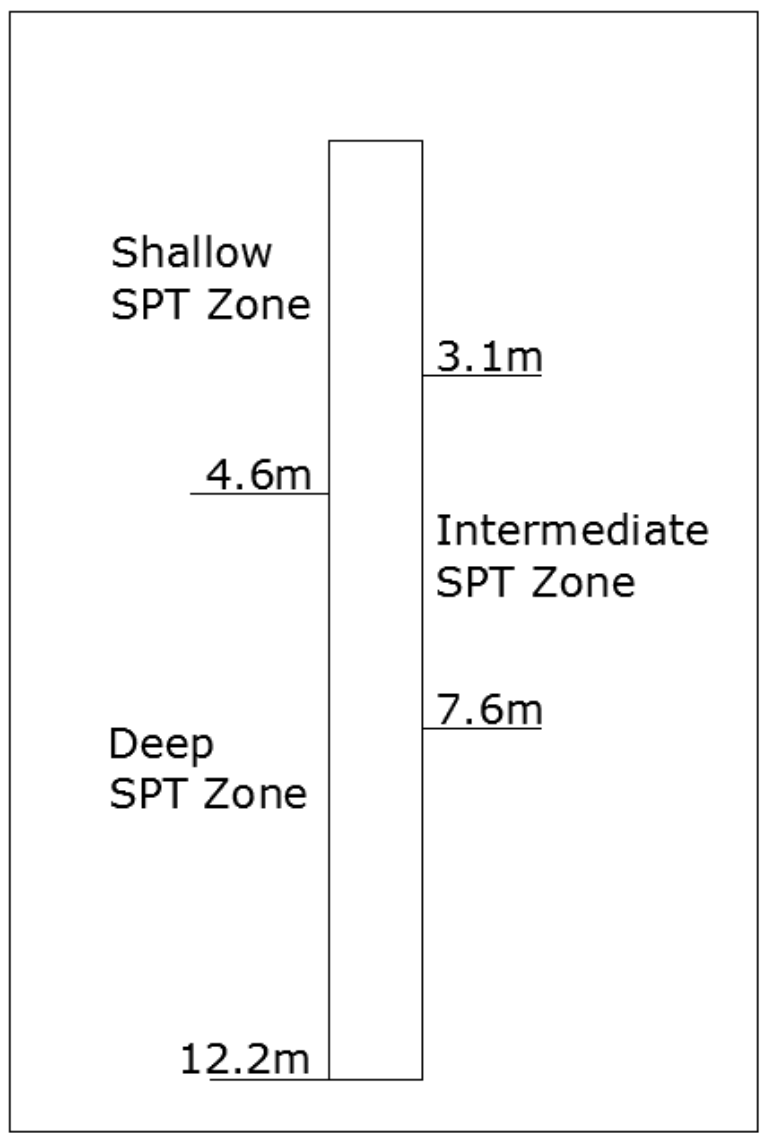

Figure 2. SPT zones defined for use in the statistical analysis. For each boring, the average $\mathrm{N}$-value and the minimum $\mathrm{N}$-value are found for each of the three depth ranges.

\section{SPT values as predictors of GPR anomalies}

Binary logistic regression is a method for describing the relationship between an independent variable that can take on a range of values (e.g. SPT) and a "yes or no" categorical dependent variable (e.g. GPR anomaly). This method was applied to the entire data set of 299 SPTs. Six categories of SPT criteria were defined: the minimum SPT value observed in each of the three depth zones, and the average SPT value observed in each of the three depth zones (Table 1). For each of these six criteria, the probability of encountering a GPR anomaly at the SPT site was computed as a function of the SPT criteria value.

If there were a perfect SPT threshold predictor of the presence of a GPR anomaly, SPT values lower than the specific threshold would be $100 \%$ correlated with the presence of a GPR anomaly, and the probability of a 
Table 1. SPT criteria used in statistical analyses for Figure 3, Table 2, and Table 4.

\begin{tabular}{lll}
\hline SPT criteria & \multicolumn{1}{c}{ Description } & $\begin{array}{l}\text { Assumed threshold N-value for } \\
\text { sinkhole potential used in odds } \\
\text { ratio analysis }\end{array}$ \\
\hline ShallowA & Average SPT value over the depth range 0-4.6 m & Average SPT $<10$ \\
ShallowM & Minimum SPT value over the depth range $0-4.6 \mathrm{~m}$ & Minimum SPT $<4$ \\
IntermediateA & Average SPT value over the depth range 3.1-7.6 m & Average SPT $<15$ \\
IntermediateM & Minimum SPT value over the depth range 3.1-7.6 m & Minimum SPT $<4$ \\
DeepA & Average SPT value over the depth range 4.6-12.2 m & Average SPT $<20$ \\
DeepM & Minimum SPT value over the depth range 4.6-12.2 m & Minimum SPT $<5$ \\
\hline
\end{tabular}

GPR anomaly would be 1 for all SPT values below the threshold criteria. The probability would then decrease abruptly to zero at the threshold SPT value and remain at zero for higher SPT values. Thus in Figure 3, the sharper the plunge in the probability curve, the better the predictive capability of that variable for associated GPR anomalies. Figure 3 shows that sites with no low SPT values, i.e. those with high minimum SPT values, indeed have a low probability of showing a GPR anomaly. The figure also shows that SPTs with the lowest minimum values have $\sim 60-70 \%$ probability of correctly predicting the presence of a GPR anomaly.

Figure 3 shows the probability of a coincident GPR anomaly for 5 of the 6 SPT criteria. (The 6 th criteria did not satisfy the confidence level described below.)

Figure 3 shows that as the minimum SPT value in the shallow zone (0-4.6 $\mathrm{m})$ ranges from 0 (very loose soil) to 20 (compact soil), the probability of finding a GPR anomaly will decrease by $84 \%$ (from $70 \%$ to $11 \%$ ). Minimum SPT values in the intermediate zone are less good predictors of GPR anomalies: from minimum values of 0 to 20 the probability of a coincident GPR anomaly drops by $68 \%$ (from $59 \%$ to $19 \%$ ). Minimum SPT values in the deep zone show the weakest correlation: from 0 to 20 the probability drops by only $23 \%$ (from $55 \%$ to $42 \%$ ).

For each of the six categories in Table 1, the model fit statistics are tested with Wald chi-square analysis (Table 2). The confidence level is set to $90 \%$, and results are shown only where there is at least a $90 \%$ confidence level of rejecting the null hypothesis of zero logistic regression coefficient. (A coefficient of 0 would correspond to a flat line across Figure 3.) $90 \%$ confidence corresponds to a P-value of 0.10 or less in the third column of Table 2. The SPT criteria for the shallow zones show much lower P-values than for intermediate and deeper zones in general. This implies that SPT criteria from shallow zones are better predictors of the presence of a GPR anomaly.

The imperfect correlations between SPT values and GPR anomalies could be explained by a variety of phenomena. In cases where low $\mathrm{N}$-values are present without corresponding GPR anomalies, possible explanations include (a) partially saturated unconsolidated sediment may be naturally loose without being disturbed by sinkhole activity; (b) GPR surveys may not be effective at imaging some sinkhole-related anomalies due to poor penetration in the presence of a shallow clay layer or

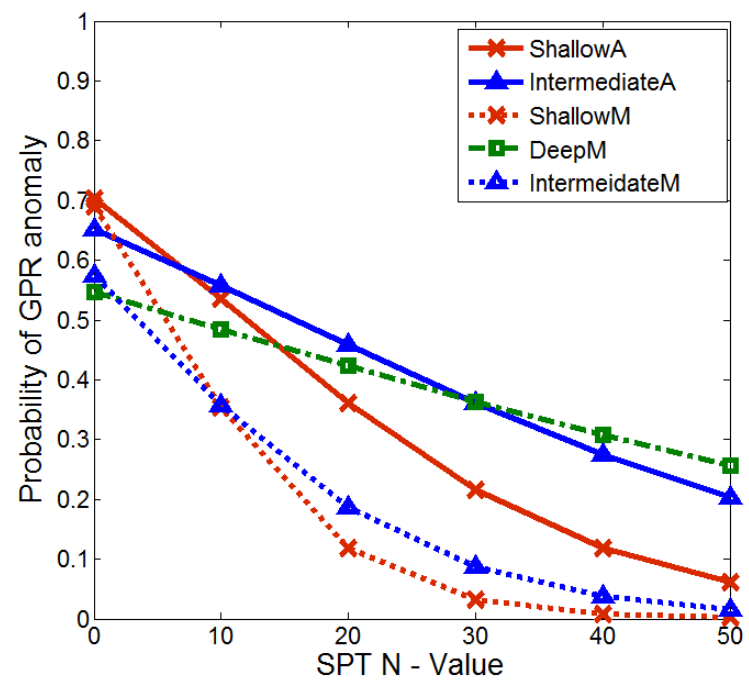

Figure 3. Logistic regression results for the 5 SPT categories (Table 1) that satisfy the $90 \%$ confidence level criteria. The horizontal axis shows the average of or minimum $\mathrm{N}$-value over the defined depth range. The vertical axis shows the probability of observing a GPR anomaly coincident with the SPT location. Zero correlation would appear as a horizontal line. A perfect SPT threshold criterion would appear as a vertical line that would drop from 1 to 0 at the threshold $\mathrm{N}$-value. 
Table 2. Model fit statistics for logistic regression shown in Figure 3. ${ }^{*}=$ not significant at $90 \%$ confidence.

\begin{tabular}{|c|c|c|}
\hline \multicolumn{3}{|c|}{ Model fit test } \\
\hline $\begin{array}{c}\text { SPT } \\
\text { Criteria }\end{array}$ & $\begin{array}{l}\text { Wald Chi- } \\
\text { Square }\end{array}$ & P-value \\
\hline ShallowM & 11.18 & $<0.01$ \\
\hline IntermediateM & 8.19 & $<0.01$ \\
\hline DeepM & 2.64 & 0.10 \\
\hline ShallowA & 12.42 & $<0.01$ \\
\hline Intermediate $\mathrm{A}$ & 2.66 & 0.10 \\
\hline DeepA & 0.58 & $0.45^{*}$ \\
\hline
\end{tabular}

absence of shallow reflectors; or (c) there may be no near-surface anomalies over a growing void, as in the case of cover-collapse sinkholes (e.g. Tihansky, 1999).

Conversely, cases where GPR anomalies are recorded but without underlying low SPT N-values could be attributed to (a) GPR anomalies that represent features of sinkholes that are no longer active; or (b) active sinkholes with shallow cohesive soil layers that gradually deform downward as one unit without disturbing its overall stiffness or density. Finally, one phenomenon that could explain both cases is simply a scenario in which GPR anomalies and low SPT N-values associated with a common sinkhole are nevertheless spatially offset from each other. For example, material migrating into a cavity may migrate laterally or along an inclined path, contrary to the simple assumption of a vertical path.

\section{GPR anomalies as predictors of low $\mathbf{N}$-value SPT results}

To assess the degree to which GPR surveys improve the odds of locating boreholes with low $\mathrm{N}$-value SPTs requires an analysis with GPR anomalies as the independent variable. One applicable statistical method is odds ratio (OR) analysis.

The odds ratio is simply the ratio of the probability of observing a low SPT value on boreholes drilled on GPR anomalies to those drilled outside GPR anomalies. An odds ratio of 1 indicates that the odds of finding a low SPT are equal for boreholes drilled inside and outside GPR anomalies. An odds ratio greater than 1 indicates that the odds of finding a low SPT value are higher for boreholes drilled on GPR anomalies. To compute an odds ratio requires that we define "low SPT value", as well as "on GPR anomaly" vs. "outside GPR anomaly". For this purpose, the six SPT criteria of Table 1 are used, and four GPR group classifications are defined as in Table 3. To use odds ratio analysis a threshold SPT value must be defined; if the SPT criteria falls below this threshold value, then the SPT is considered "low". The threshold values are listed in Table 1. For example, when the SPT criteria is the average value over the shallow zone (0$4.6 \mathrm{~m}$ ), this average $\mathrm{N}$-value must fall beneath 10 to be called "low" SPT (first line of Table 1).

The threshold criteria were defined using a two-step procedure. First, an optimization code searched for the threshold that showed the strongest correlation between the GPR and SPT results for the entire 103-site data set. The threshold values were then subjectively shifted slightly to values that hold geological significance in order to facilitate comparison with other studies. For example, an optimal threshold $\mathrm{N}$-value of less than 4 was shifted to 4, which corresponds to a commonly used definition for "very low" N-value (Terzaghi and Peck, 1948).

The presence or absence of GPR anomalies can be defined for residential sites or for individual boreholes. Table 3 shows the four GPR group classifications described here. For each of the GPR group classifications, the odds ratios were computed for the six SPT criteria. The results are shown in Table 4. For inclusion in Table 4, we require that the null hypothesis (an odds ratio of 1) can be rejected at the confidence level of $90 \%$. (This corresponds to P-values less than 0.1 in Table 4.)

Table 4 shows that regardless of the GPR anomaly group classification, using GPR anomalies to locate boreholes improves the odds of finding low minimum SPT values in the shallow and intermediate depth zones, in effect from 0 to 7.6 meters. ("Low" is defined as a minimum $\mathrm{N}$-value less than 4 for both depth zones.) We note that in most cases the odds ratios computed using minimum SPT N-value criteria are higher than corresponding odd ratios using average SPT N-value. The odd ratios are also generally highest for shallow zones, lower for intermediate zones, and lowest or statistically insignificant for the deep zones. The overall highest odds ratios are found when GPR anomaly classification is made using group 4 (Table 4).

Several aspects of this statistical analyses support the hypothesis that GPR anomalies may be associated with, but laterally offset from low SPT borings. Odds ratios for group 2 classification are lower than for 
Table 3. Classifications for spatial correlation between SPTs and GPR anomalies.

\begin{tabular}{|l|l|l|l|}
\hline \multirow{2}{*}{$\begin{array}{l}\text { GPR } \\
\text { GROUP }\end{array}$} & \multicolumn{2}{|l|}{ Residential sites with at least one GPR anomaly } & Residential sites with no GPR anomalies \\
\cline { 2 - 4 } & Boreholes drilled on GPR anomalies & $\begin{array}{l}\text { Boreholes drilled outside } \\
\text { GPR anomalies }\end{array}$ & Boreholes drilled outside GPR anomalies \\
\hline Group 1 & $\begin{array}{l}\text { Boreholes drilled on residential sites } \\
\text { with GPR anomalies }\end{array}$ & $\begin{array}{l}\text { Boreholes drilled on residential sites with } \\
\text { no GPR anomalies }\end{array}$ \\
\hline Group 2 & Boreholes drilled on GPR anomalies & Boreholes drilled outside GPR anomalies \\
\hline Group 3 & $\begin{array}{l}\text { Boreholes located on sites with GPR } \\
\text { anomalies and drilled inside the GPR } \\
\text { anomalies }\end{array}$ & $\begin{array}{l}\text { Boreholes located on sites } \\
\text { with GPR anomalies but } \\
\text { drilled outside the GPR } \\
\text { anomalies }\end{array}$ & \\
\hline Group 4 & $\begin{array}{l}\text { Boreholes located on sites with GPR } \\
\text { anomalies and drilled inside the GPR } \\
\text { anomalies }\end{array}$ & & $\begin{array}{l}\text { Boreholes drilled on residential sites with } \\
\text { no GPR anomalies }\end{array}$ \\
\hline
\end{tabular}

Table 4. Odds ratio analysis results for SPT categories with ratios significantly different from 1 . The odds ratio is the ratio of the probability of observing a SPT value below the threshold on boreholes drilled on GPR anomalies to that for boreholes drilled outside GPR anomalies An odds ratio > 1 implies that GPR data "add value", in that SPTs on GPR anomalies are more likely to encounter zones with N-values below the threshold.

\begin{tabular}{|c|c|c|c|c|c|c|}
\hline $\begin{array}{l}\text { Data } \\
\text { Group }\end{array}$ & $\begin{array}{l}\text { SPT } \\
\text { Criteria }\end{array}$ & SPT Zone & $\begin{array}{l}\text { Depth } \\
\text { Range (m) }\end{array}$ & $\begin{array}{l}\text { SPT } \\
\text { Threshold value }\end{array}$ & $\begin{array}{l}\text { Odds Ratio for ob- } \\
\text { serving SPT below } \\
\text { threshold based on } \\
\text { GPR anomaly }\end{array}$ & P-value \\
\hline \multirow[t]{3}{*}{ Group 1} & Average & Shallow & $0-4.6$ & 10 & 2.22 & 0.0001 \\
\hline & \multirow[t]{2}{*}{ Minimum } & Shallow & $0-4.6$ & 4 & 2.27 & 0.0001 \\
\hline & & Intermediate & $3.1-7.6$ & 4 & 1.63 & 0.0156 \\
\hline \multirow[t]{4}{*}{ Group2 } & \multirow[t]{2}{*}{ Average } & Shallow & $0-4.6$ & 10 & 2.00 & 0.0017 \\
\hline & & Intermediate & $3.1-7.6$ & 15 & 1.76 & 0.0064 \\
\hline & \multirow[t]{2}{*}{ Minimum } & Shallow & $0-4.6$ & 4 & 2.63 & 0.0001 \\
\hline & & Intermediate & $3.1-7.6$ & 4 & 1.39 & 0.0376 \\
\hline \multirow[t]{6}{*}{ Group 3} & \multirow[t]{3}{*}{ Average } & Shallow & $0-4.6$ & 10 & 1.41 & 0.0641 \\
\hline & & Intermediate & $3.1-7.6$ & 15 & 1.84 & 0.0147 \\
\hline & & Deep & $4.6-12.2$ & 20 & 1.95 & 0.107 \\
\hline & \multirow[t]{3}{*}{ Minimum } & Shallow & $0-4.6$ & 4 & 1.77 & 0.0188 \\
\hline & & Intermediate & $3.1-7.6$ & 4 & 2.24 & 0.0062 \\
\hline & & Deep & $4.6-12.2$ & 5 & 1.35 & 0.0709 \\
\hline \multirow[t]{4}{*}{ Group 4} & \multirow[t]{2}{*}{ Average } & Shallow & $0-4.6$ & 10 & 2.57 & 0.0001 \\
\hline & & Intermediate & $3.1-7.6$ & 15 & 1.70 & 0.0159 \\
\hline & \multirow[t]{2}{*}{ Minimum } & Shallow & $0-4.6$ & 4 & 2.89 & 0.0001 \\
\hline & & Intermediate & $3.1-7.6$ & 4 & 2.35 & 0.0019 \\
\hline
\end{tabular}


group 4. Group 2 compares all boreholes drilled on GPR anomalies against all boreholes drilled outside GPR anomalies, irrespective of the presence of other possible GPR anomalies at a given residential site. In contrast group 4 classifications compares boreholes drilled on GPR anomalies against only boreholes drilled on residential sites with no GPR anomalies. This latter grouping (group 4) excludes boreholes drilled outside GPR anomalies but located in residential sites with GPR anomalies. The higher odds ratio for group 4 suggests that on sites with GPR anomalies, nearby boreholes are more likely to encounter low N-values.

Another result supporting the above hypothesis is the observation that minimum N-value criteria show better correlation with GPR anomalies than average $\mathrm{N}$-value criteria, for both logistic regression analysis and odds ratio analysis. This suggests that sinkhole-related low N-values zones are thinner than the extent of the defined depth zones (0-4.6 $\mathrm{m}$ or 3.1-7.6 m). If cavities were vertically below GPR anomalies, one should expect consistently low N-values in all zones of a vertical borehole. So a given vertical borehole may only encounter a portion of an inclined disturbed low N-value zone.

Finally, a third result supports the hypothesis that inclined zones of low $\mathrm{N}$-values terminate at GPR anomalies at the surface. Minimum N-value criteria for shallow depths (0$4.6 \mathrm{~m}$ ) show stronger correlation with the presence of GPR anomalies than the criteria for intermediate depths (3.1-7.6 $\mathrm{m})$. N-values at deepest depth ranges (4.6-12.2 m) show the weakest or insignificant correlations. These are observed in both the logistic regression and odd ratio measures.

\section{Conclusions}

Sinkhole related features identified on GPR images and SPT values within three depth ranges were used to examine relationships between GPR anomalies and SPT N-values at 103 residential sites in west-central Florida. Logistic regression analysis was used to examine SPT values as an indicator of sinkhole-related GPR anomalies, and odd ratios were computed for GPR anomalies as predictors of low SPT values. Both methods show statistically significant correlations between GPR anomalies and zones of low SPT N-values at depth ranges of 0-4.6 $\mathrm{m}$ and 3.1-7.6 m. Both methods show the strength of the correlation decreases with depth. The strongest correlations are observed when low-SPT threshold criteria are based on minimum SPT values rather than average SPT values over a given depth range. Taken together, these observations suggest that raveling zones that connect voids to the surface may be inclined, such that shallow GPR anomalies are laterally offset from deeper zones of low N-values. Future analysis of this data set will seek to account for the effects of soil type, shallow clay layers, overburden sediment thickness, geology, and geomorphology on the correlation between sinkhole-related GPR anomalies and SPT values.

\section{References}

Carter M, Symons MV, 1989. Site Investigations and Foundations Explained. London: Pentech Press limited.

Dobecki TL, Upchurch SB. 2006. Geophysical applications to detect sinkholes and ground subsidence: The Leading Edge. 25 (3): 336-341.

"Florida Department of Environmental Protection (FDEP). [updated 22 Jan. 2013; cited 23 Jan. 2013]. Available from: http://www.dep.state.fl.us/ gis/datadir.htm.

Frank EF, Beck BF. 1991. An Analysis of the Cause of Subsidence Damage in the Dunedin, Florida Area 1990/1991: Florida Sinkhole Research Institute, University of Central Florida, Orland, Florida.

Florea L 2006. Architecture of Air-Filled Caves within the Karst of the Brooksville Ridge, West-Central Florida: Journal of Cave and Karst Studies 68(2): 64-75.

Meyerhof GG.1956. Penetration tests and bearing capacity of cohesionless soils, Proceedings ASCE 82(1):1-19.

Peck RB, Hanson WE, Thornburn T. 1974. Foundation engineering.2nd ed. New York(NY):John Wiley and Sons.

Schmidt, W. 2005. Geological and Geotechnical Investigation Procedures For Evaluation of the Causes of subsidence Damage In Florida. Florida Geological Survey Special Publication No. 57.

Scott TM, 1988, The Lithostratigraphy of the Hawthorn Group (Miocene) of Florida: Florida Geological Survey, Bulletin 59:1- 148 p.

Sinclair WC, Stewart JW, Knutilla, RL, Gilboy AE, Miller, RL. 1985. Types, features and occurrence of sinkholes in the karst of west-central Florida: U.S. Geological Survey, Water-Resources Investigations Report. 85 (4126): 81 p.

Terzaghi, K, and Peck RB. 1948. Soil Mechanics in engineering practice. New York (NY): John Wiley \& Sons.

Tihansky AB, 1999. Sinkholes, west-central Florida-A link between surface water and ground water. United States Geological Survey Circular 1182: 121 - 140.

Zisman ED. 2001. A Standard Method for Sinkhole detection in the Tampa, Florida, Area: Environmental and Engineering Geoscience 7(1): 31 -50. 
254 NCKRI SYMPOSIUM 2 I3TH SINKHOLE CONFERENCE 